\title{
POLÍTICA E ECONOMIA NA JURISDIÇÃO CONSTITUCIONAL ABSTRATA (I999-2004)
}

\author{
Ricardo Silveira Ribeiro
}

POLITICS AND ECONOMICS IN ABSTRACT JUDICIAL REVIEW (1999-2004)

\section{RESUMO}

O PRESENTE ARTIGO INSERE-SE NA ÁREA DE INVESTIGAÇÃO DENOMINADA POLÍTICA JUDICIAL. A PARTIR DA HIPÓTESE DE QUE O SUPREMO TRIBUNAL FEDERAL (STF) AGE COMO ÓRGÄO DE GOVERNO, TESTOU-SE A INFLUÊNCIA DE VARIÁVEIS POLÍTICA, ECONÔMICA E JURÍDICA NOS JULGAMENTOS DAS AÇÕES DIRETAS DE INCONSTITUCIONALIDADE POR AÇÃO ENTRE OS ANOS 1999 E 2004. PARA ISSO, FOI CONSTRUÍDO UM BANCO DE DADOS COM JULGAMENTOS DE 162 CASOS ENVOLVENDO DECISÕES EM QUESTÕES DE ESTADO E, ATRAVÉS DA UTILIZAÇÃO DO MODELO ESTATíSTICO DE REGRESSÃO LOGÍSTICA, CHEGOU-SE A CONCLUSÕES SIGNIFICATIVAS: O STF É SENSÍVEL A DETERMINADOS ATORES EM DETRIMENTO DE OUTROS, DECLARA A INCONSTITUCIONALIDADE QUANDO A NORMA TRAZ IMPACTO NEGATIVO NAS FINANÇAS DO ESTADO E JULGA DE ACORDO COM A AGENDA DO PRESIDENTE. COMO CONCLUSÃO, VERIFICOU-SE QUE A CORTE POSSUI UM COMPORTAMENTO MÚLTIPLO, ORA SE DEIXANDO INFLUENCIAR POR VARIÁVEIS JURÍDICAS, ORA DECIDINDO POR MOTIVAÇÕES DE ORDEM POLÍTICA OU ECONÔMICA, SEGUNDO A LÓGICA EVIDENCIADA ACIMA.

\section{PALAVRAS-CHAVE}

Supremo Tribunal Federal; Política Judicial; Jurisdição CONSTITUCiOnal abstrata; Política constitucional; JUDICIALIZAÇÃO DA POLÍTICA.

\begin{abstract}
THIS ARTICLE IS RELATED TO AN AREA OF INVESTIGATION CALLED JUDICIAL POLITICS. BASED ON THE HYPOTHESIS THAT BRAZILIAN SUPREME COURT (STF) ACTS AS A GOVERNMENT BODY, IT WAS TESTED THE INFLUENCE OF POLITICAL, ECONOMIC, AND JURIDICAL VARIABLES ON ABSTRACT JUDICIAL REVIEW DECISIONS FROM 1999 TO 2004. FOR THAT PURPOSE, A DATASET OF 162 CASES CONCERNING JUDICIALIZATION OF STATE POLITICS WAS DEVELOPED. USING LOGISTIC REGRESSION, IT WAS CONCLUDED THAT THE STF IS MORE SENSIBLE TO CERTAIN GROUPS OF ACTORS THAN OTHERS, DECLARES THE UNCONSTITUTIONALITY OF

LEGISLATION WHEN THIS LEGISLATION BRINGS NEGATIVE IMPACT ON STATE FINANCES AND JUDGE IN FAVOR OF

PRESIDENTS' AGENDA. AS A CONCLUSION, WE VERIFIED THAT BRAZILIAN SUPREME COURT DECIDES IN SUCH A MULTIPLE BEHAVIOR, SOMETIMES LETTING ITSELF BEING INFLUENCED BY LEGAL VARIABLES, SOMETIMES DECIDING MOTIVATED BY POLITICAL OR ECONOMICAL VARIABLES, ACCORDING TO THE LOGIC DEMONSTRATED.
\end{abstract}

\section{KEYWORDS}

BRAZILIAN SUPREME COURT; JUDICIAL POLITICS; ABSTRACT JUDICIAL REVIEW; CONSTITUTIONAL POLITICS;

JUDICIALIZATION OF POLITICS.

\section{INTRODUÇÃO}

Teorias jurídicas normativas gostariam de ver, no Supremo Tribunal Federal, uma Corte voltada para agir de acordo com pautas estritamente jurídicas, pois, ao ver 
dessas, as decisões do STF não deveriam ser motivadas por razões de ordem política e/ou econômica. Pesquisas empíricas sobre essa Corte, contudo, revelaram que o STF, longe de ser um órgão judicial neutro, age como verdadeiro policy maker, um órgão de governo, sendo sensível às diversas circunstâncias do ambiente, especialmente quando julga no âmbito da jurisdição constitucional abstrata.

A ênfase de tais pesquisas, entretanto, tende a recair na investigação de variáveis estritamente políticas, deixando de mensurar o papel de eventuais variáveis econômicas relevantes ao processo decisório. Assim, muito pouco foi teorizado sobre a lógica geral do processo decisório dessa Corte até então, especialmente a partir de análises quantitativas inferenciais.

Procurando suprir essas lacunas, este artigo testa o papel conjunto de variáveis de ordem econômica, jurídica e política no processo decisório da Corte Constitucional brasileira e, em especial, deseja demonstrar que o STF, ao declarar a constitucionalidade ou inconstitucionalidade de normas, é movido por essas múltiplas variáveis de forma relativamente racionalizada.

Quanto à organização, o texto está divido em três partes. A primeira pretende fazer uma rápida revisão das principais investigações empíricas já realizadas acerca do comportamento do Supremo Tribunal Federal. A seguir apresentamos uma explanação sobre a metodologia estatística utilizada para investigar a lógica do processo decisório do STF nas Ações Diretas de Inconstitucionalidade por Ação. Por fim, tomaremos em consideração os resultados das análises estatísticas, para que possamos compreender o comportamento do STF em bases mais realistas.

Ao fim desse processo, esperamos chegar a um modelo explicativo provisório do processo decisório do Supremo Tribunal Federal ao julgar Ações Diretas de Inconstitucionalidade por Ação no período de 1999 a 2004, delimitação temporal escolhida.

\section{Pesquisas empíricas sobre a Jurisdição constitucional abstrata}

Análises positivas do comportamento do Supremo Tribunal Federal são extremamente recentes. Trabalhos mais robustos datam do início dos anos 1990 e, em termos práticos, ainda não foram capazes de gerar uma linha de pesquisa consistente em política judicial no Brasil, embora já existam estudos relativamente antigos sobre o Poder Judiciário e sua relação com a sociedade (cf. Sadek, 2002, p. 233-265; Junqueira, 1993, p. 91-124).

De maneira geral, essas análises positivas podem ser subdivididas em dois eixos metodológicos centrais: (1) tentativas de demonstrar a sensibilidade do Supremo Tribunal Federal às variáveis políticas por meio de estudos de caso; e (2) análises estatísticas das decisões do Supremo Tribunal Federal.

No primeiro eixo existem dois autores bem representativos, Oscar Vilhena Vieira e Rogério Bastos Arantes. Em comum, ambos procuraram demonstrar como 
o comportamento decisório do STF é sensível às variáveis de ordem política e ao ambiente em geral. Dessa forma, o Tribunal não se limitaria a ser uma mera instituição de caráter estritamente jurídico; seria, mais do que isso, uma instituição de natureza política e, portanto, sua aplicação de normas constitucionais seria motivada pela lógica do cálculo político.

O estudo de Arantes sobre a atuação do STF no controle de constitucionalidade do Plano Collor I salientou que a Constituição de 1988 deu origem a um duplo movimento, de diferenciação e de centralização política. De um lado, novos desenhos institucionais possibilitaram o surgimento de órgãos judiciais e de competências que terminaram por garantir uma diferenciação maior do STF perante os outros Tribunais Superiores. Por outro lado, o próprio governo passou a sentir a necessidade de centralizar poder em suas mãos, para que as políticas pudessem ser implementadas de maneira estável, isto é, sem riscos adicionais de múltiplos enfrentamentos na via judicial. Esse duplo movimento acarretou uma concentração de poderes nas mãos do STF em detrimento dos demais órgãos judiciais (Arantes, 1997, p. 108ss).

Foi nesse novo quadro institucional que o sistema "híbrido" (misto) de controle de constitucionalidade tomou sua forma mais acabada, pois, cada vez mais, o Judiciário passou a ser uma arena política de embate entre os atores políticos nas esferas difusa e concentrada (Arantes, 1997, p. 110). Houve um aumento das tensões entre a atividade de governo e a atividade estritamente jurisdicional, supostamente neutra e somente afeita a argumentos jurídicos.

Para Arantes, isso pôde ser observado claramente no período de implementação da política de estabilização monetária do governo Collor. Naquele momento, o presidente emitiu uma sucessão de medidas provisórias que suscitaram severos questionamentos judiciais nas vias difusa e concentrada. Enquanto, na via difusa, os juízes tenderam a decidir de maneira contrária aos anseios do chefe do Poder Executivo, o STF oscilou entre defender a Constituição e ceder aos "imperativos de governo" na via concentrada (Arantes, 1997, p. 199).

Arantes não viu, portanto, qualquer vantagem na adoção do sistema misto de controle de constitucionalidade pela nossa Constituição, pois o modelo aumentaria a probabilidade de crises de governabilidade e de insegurança jurídica. Julgou, então, que o papel normativo do STF seria anular normas de constitucionalidade duvidosa nos momentos de "tensão entre o respeito à Constituição e os imperativos de governo” (Arantes, 1997, p. 204). O comportamento político do STF, dúbio ou oscilante, parece ser condenável aos olhos desse autor.

Com abordagem metodológica semelhante, Vieira (1994) analisou um número maior de casos. O diagnóstico geral foi o que alterações institucionais decorrentes da Constituição de 1988 foram responsáveis pela ampliação dos poderes políticos do STF, aproximando essa Corte das autoridades políticas. Em casos estratégicos, também o STF 
atuou de maneira ambígua, segundo o autor, pois deixou de basear-se em reflexões meramente normativas e passou a fundar seus argumentos em uma ética de resultados. Ao fazer isso, "atuou como órgão de governo" (Vieira, 1994, p. 96, 144).

A partir das pesquisas de Vieira e de Arantes, é possível concluir que o STF não atua segundo critérios estritamente jurídicos de direito positivo. Os autores, contudo, por razões normativas, parecem ter uma grande resistência em aceitar o STF como legítimo órgão de governo. Longe de verem o comportamento político como uma decorrência normal do processo decisório, ambos o visualizam como uma anomalia, diante das tarefas normativas da Corte, especialmente a de ser a guardiã da Constituição.

$\mathrm{Na}$ literatura a respeito de política judicial, entretanto, o comportamento político das Cortes tende a ser visto como "normal", embora haja certa divergência sobre quais seriam as variáveis explicativas mais importantes, se as preferências políticas sinceras dos juízes (cf. Segal, 1997 e Segal; Spaeth, 2002) ou as ações estratégicas dos magistrados, quando da adoção de votos sofisticados (cf. Epstein; Knight, 1998; Perry, 1991; Bergara; Richman; Spiller, 2002). Essa literatura leva-nos a concluir que a suposta oscilação do STF, em verdade, é inerente ao comportamento de qualquer Corte, sendo uma decorrência de incentivos presentes no próprio processo decisório, e não um "problema", em si, do STF, a ser combatido.

Quanto às abordagens estatísticas, Castro (1993; 1997) foi, certamente, o precursor das primeiras investigações acerca do comportamento do Supremo Tribunal Federal nas Ações Diretas de Inconstitucionalidade. Em trabalho publicado em 1993, ele trouxe, ao público, dados quantitativos sobre o processo decisório no Supremo Tribunal Federal ao analisar 115 Ações ajuizadas por partidos políticos até fevereiro de 1993.

De acordo com esse autor, a área temática mais proeminente estava relacionada à contestação das políticas econômicas do governo (política monetária, política fiscal e política de rendas) e, em segundo e terceiro lugares, respectivamente, as contestações à política local e às regras eleitorais (Castro, 1993, p. 31-33). Por outro lado, enquanto os partidos de esquerda se valiam das Ações para questionar a política econômica do governo, os partidos de direita usaram-nas para contestar as regras eleitorais e a política local (Castro, 1993, p. 39ss).

Quanto às Ações ajuizadas pelas confederações e pela $\mathrm{OAB}$, seus números foram significativamente menores. $\mathrm{O}$ autor, inclusive, salienta diferenças substanciais nas questões levadas ao STF. Enquanto os partidos políticos buscaram concretizar uma redistribuição de renda, as confederações, por serem entidades de natureza patronal, procuraram declarar a inconstitucionalidade das medidas redistributivas. A OAB, por fim, ajuizou Ações de natureza corporativa, isto é, em defesa de seus interesses, diante da estrutura do Poder Judiciário e da ordem processual (Castro, 1993, p. 43-45).

A partir desses resultados, Castro esboçou algumas "conclusões provisórias" acerca do controle de constitucionalidade no STF. Em primeiro lugar, o STF passou 
a ser um novo canal de "inovação institucional” na política brasileira, dada a atuação dos partidos políticos nesse novo âmbito. Com certo otimismo, o autor viu, na jurisdição constitucional, uma espécie de arena na qual, através de provocação, seria possível redirecionar as políticas econômicas, de sorte a podermos avançar em prol de uma política mais condizente com o interesse público. A despeito disso, ele reconheceu que esse novo canal não supre os "problemas de representação" (Castro, 1993, p. 51).

Haveria, assim, nas palavras de Castro, uma espécie de "vazio institucional", ainda a ser explorado pelos partidos que buscam maior justiça social. Para ele, o STF poderia funcionar como um lócus no qual uma agenda política alternativa poderia ser implementada, desde que as políticas macroeconômicas passassem a ser concebidas como resultantes da política - e não da técnica - e houvesse uma reestruturação institucional apta a aproveitar "o potencial da mobilização social” (Castro, 1993, p. 55-56).

Em outra linha de pesquisa, o segundo trabalho de Castro (1997, p. 152) deitou atenção sobre a análise de 1.240 ementas de Acórdãos publicados no Diário de Justiça da União no primeiro semestre de 1994. Entre seus principais resultados, destaquese a descoberta de que o STF julgou três quartos dos casos da amostra em favor de pessoas privadas. Em sua maioria, foram casos que versavam sobre tributos ou matérias de ordem processual. Nas demais áreas temáticas, entretanto, aí não inclusas as criminais, o autor detectou que o STF decidiu em favor do Estado duas vezes mais que os particulares, e, como conclusão, raciocinou que o STF não desenvolveu uma jurisprudência de proteção aos direitos individuais, salvo em matéria tributária (Castro, 1997, p. 153-154).

A mais vasta análise de dados, no entanto, adveio da pesquisa de Vianna e colaboradores (1999). Com um estudo estatístico-descritivo de 1.935 Ações Diretas de Inconstitucionalidade ajuizadas entre os anos 1988 e 1998, esses autores inauguraram uma série de discussões nesse novel campo de pesquisa no Brasil. A hipótese central da pesquisa é que a judicialização da política, no Brasil, vem ocorrendo junto ao STF por pressão dos diversificados legitimados ativos. Com isso, "a iniciativa dos intérpretes da Constituição, constantemente no recurso às Ações Diretas de Inconstitucionalidade, estaria induzindo uma atitude mais favorável por parte do STF no que se refere à assunção de novos papéis", embora os autores enfatizem que concordam com a assertiva corrente de que o Judiciário vem oferecendo "resistência" ao desempenho do papel de "personagem central no processo de judicialização da política” (Vianna et al., 1999, p. 53).

Para os autores, a presença constante dos legitimados ativos no processo de judicialização da política torna a mesma diversificada. Haveria, então, um "caráter dúplice" nessa judicialização: de um lado, as Ações dos partidos políticos representariam a típica ação da minoria contra a maioria parlamentar; de outro, as provocações 
dos governadores e do procurador-geral da República fugiriam desse modelo, pois são Ações em busca da racionalização da Administração Pública no âmbito estadual (Vianna et al., 1999, p. 58, 68).

Grande parte do trabalho desses estudiosos, então, passa a ser dedicada a compreender o que os autores denominaram de "dimensão ativa" da judicialização da política, para compreender quem provoca a jurisdição constitucional e quais são as principais características temáticas dessa provocação. Há poucos insights, entretanto, sobre como o STF se comporta, diante dessas provocações. Nesse sentido, a parte do livro dedicada ao julgamento das Ações Diretas de Inconstitucionalidade é, teoricamente, pouco esclarecedora e a abordagem, muito mais descritiva.

Os autores salientam que a atuação do STF não pode ser considerada passiva ou condescendente com a agenda do Poder Executivo. Antes disso, embora a atuação do STF fosse cautelosa, houve um elevado número de suspensões da eficácia de normas em sede de liminar. O diagnóstico geral foi que o STF teve preferência por declarar a inconstitucionalidade de normas estaduais atacadas por governadores e pelo procurador-geral da República. Também, o STF preferiu apreciar a constitucionalidade de normas liminarmente, pois poucas Ações Diretas de Inconstitucionalidade foram julgadas definitivamente até o fim da pesquisa dos autores (Vianna et al., 1999, p. 117). Ademais, os legitimados melhor sucedidos foram os governadores e o procurador-geral da República. Nos casos quantificados, foram eles que mais conseguiram vitórias diante dos demais grupos (Vianna et al., 1999, p. 119). Segue uma breve descrição dos resultados:

I. Os Governadores contestaram normas constitucionais relativas ao direito administrativo e atuaram em prol da governabilidade. Em suas Ações, foram mais bem-sucedidos ao contestarem normas do Poder Legislativo Estadual e dos Tribunais de Contas que atribuíam direitos aos servidores públicos. Quando questionaram normas federais, contudo, não foram bem-sucedidos (Vianna et al., 1999, p. 121ss).

II. O procurador-geral da República foi o ator que obteve maior sucesso na concessão de cautelares e nas decisões definitivas de mérito. Foi bemsucedido, inclusive, ao contestar normas federais advindas do Poder Judiciário e normas estaduais dos Poderes Legislativo e Judiciário. Tal qual fizeram os Governadores, a Procuradoria Geral da República procurou questionar temas relacionados ao direito administrativo. Em especial, os relativos à concessão de remunerações aos servidores e aos magistrados (Vianna et al., 1999, p. 123ss).

III. Os autores entenderam que, a partir de 1994, o STF passou a ser mais sensível às provocações dos partidos políticos, declarando, portanto, a 
inconstitucionalidade de normas. Em geral, o padrão de atuação desses atores foi o mais clássico: procuraram atacar as decisões da maioria em uma arena exterior à do jogo parlamentar. No pertinente aos julgamentos, não foram bem-sucedidos, ao questionarem normas de política econômica, mas o foram quando questionaram normas de administração pública (1999, p. 127ss).

IV. As entidades empresariais foram bem-sucedidas ao questionarem normas federais que acarretaram restrições legais qualificadas pelas mesmas como indevidas). As associações de trabalhadores e profissionais, por outro lado, não foram bem-sucedidas, pois poucas foram consideradas procedentes, quando do julgamento definitivo. Os autores acentuaram, todavia, que, nas liminares, essas entidades obtiveram maior sucesso. Chegaram à conclusão de que o julgamento de mérito não é o melhor campo para que desvendemos o sentido da judicialização da política no Brasil. No pertinente, exclusivamente, às Ações das associações dos trabalhadores, obtiveram maior êxito quando questionaram normas estaduais. Quanto às normas federais, reputam que houve uma melhora débil na capacidade das associações de trabalhadores de converterem suas Ações em "um instrumento de proteção social” (Vianna et al., 1999, p. 131,134 ss).

V. As Ações ajuizadas pela OAB, por fim, foram extremamente bemsucedidas. Somente perderiam, em nível de sucesso, para as dos governadores e do procurador-geral da República. No âmbito estadual, os temas preferidos foram os relacionados ao provimento por concurso público, aos custos do acesso à justiça e à composição dos Tribunais de Justiça. No federal, versaram sobre temas mais "universalistas" (Vianna et al., 1999, p. 136).

No mesmo eixo dessas análises estatístico-descritivas, há o trabalho de Ernani Carvalho Neto (2005). Seu banco de dados combinou microdados da pesquisa de Taylor (2006) sobre o STF com o Banco Nacional de Dados do Poder Judiciário. Cobriu, assim, um total de 1.073 Ações ajuizadas contra normas federais entre os anos de 1988 e 2002 (Carvalho Neto, 2005, p. 123). Em geral, essa pesquisa de Carvalho Neto referenda grande parte das conclusões de Vianna e seus colaboradores, ao menos quanto às estatísticas descritivas dos legitimados ativos, do tipo da lei e do tópico da lei.

No concernente aos julgamentos das Ações Diretas de Inconstitucionalidade, o trabalho Carvalho Neto divergiu substancialmente da pesquisa apresentada, pois a principal conclusão é a de que o STF age com seletividade e especificidade, ao judicializar 
a política. É seletivo porque termina por atender à demanda do procurador-geral da República em detrimento dos demais atores; é específico porque suas decisões, por declararem a inconstitucionalidade de normas, se dão em área bastante delimitada. $\mathrm{Na}$ visão do autor, o STF escolheu como área de revisão a administração judicial (Carvalho Neto, 2005, p. 134-144), mas seu diagnóstico geral é de uma baixa judicialização da política:

Duas características gerais são marcantes: (i) a alta taxa de pedidos de mérito negados (foram 663 casos ou 61,8\%) e (ii) a alta taxa de decisões pendentes (foram 332 casos ou 30,9\%). Em outras palavras, em 14 anos, o Supremo Tribunal Federal resolveu interferir, no todo ou em parte, em 7,3\% dos casos. Portanto, a Corte Suprema brasileira vem decidindo boa parte das ações (quase 70\% delas); dentre estas, boa parte, quase 2/3, não recebeu nenhum tratamento de revisão; um outro montante, quase $1 / 3$, aguarda julgamento; apenas uma pequena parcela é efetivamente revisada judicialmente. O grande número de decisões contrárias a uma revisão revelam, do ponto de vista da política, uma relutância em interferir no processo legislativo (Carvalho Neto, 2005, p. 137, grifo nosso).

Vanessa de Oliveira (2005) também compartilha dessa visão. Em uma análise empírica sobre a judicialização das privatizações no STF, a autora chegou à conclusão de que a Corte, claramente, deixou de intervir na agenda de implementação do programa de privatizações do governo. Dos 39 casos demandados junto ao STF, apenas um deles, realmente, foi julgado; ela chamou atenção para o fato de que não se pode confundir o conceito de judicialização da política com o mero ajuizamento de demandas junto a um Tribunal. Este é, apenas, um primeiro momento do ciclo da judicialização que pode, ou não, levar à judicialização da política (Oliveira, 2005, p. 581-582).

A partir de estatísticas descritivas, Fadel e Maués analisaram as Ações Diretas de Inconstitucionalidade ajuizadas por partidos políticos entre 1999 e 2004; eles chegaram à conclusão de que, a despeito do substancial incremento do número de Ações desses atores, o STF pouco legitimou suas pretensões, deixando de intervir, substancialmente, no jogo político, pois vários casos permaneceram sem decisões de mérito e o STF pouco acatou os pedidos de declaração de inconstitucionalidade dos partidos políticos. A conclusão geral também foi de baixa judicialização da política: o STF não conseguiu cumprir sua missão de fornecer parâmetros de atuação para os demais atores políticos, ao menos quando as ações foram ajuizadas pelos partidos políticos (Maués e Fadel, 2006, p. 14, 22s.).

Como se vê, Vianna e colaboradores, Carvalho Neto, Oliveira e, de certa forma, Maués e Fadel tendem a perceber certa resistência do STF na assunção de seus novos papéis na judicialização da política. Esse ceticismo contrasta com números expressivos 
de procedência total ou parcial das Ações: das 2.994 Ações Diretas de Inconstitucionalidade já decididas pelo STF entre 1988 e 31 de março de 2011, 931(31,1\%) das Ações decididas foram procedentes ou procedentes em parte (STF, 2011).

Se excluirmos desses números as Ações que não foram conhecidas, teremos 931 Ações procedentes ou procedentes em parte para um total de 1.117 conhecidas (STF, 2011). Isso é algo significativo: 83,3\% das decisões finais das Ações Diretas de Inconstitucionalidade conhecidas foram pela procedência total ou parcial. É um percentual relativamente alto de declarações de inconstitucionalidade, principalmente se levarmos em consideração que, em geral, as Ações deixam de ser conhecidas por razões de ordem processual.

Certamente, boa parte dessas declarações de inconstitucionalidade pode ser explicada a partir do julgamento reiterado de casos repetitivos: a declaração de inconstitucionalidade dar-se-ia porque o STF já teria posição firmada acerca do tema e os legitimados ativos, cientes disso, aproveitariam a oportunidade de levar a discussão ao STF, de modo a conseguir a declaração de inconstitucionalidade em outra instância decisória. Nesse caso, o STF, apesar de declarar a inconstitucionalidade em inúmeras Ações, somente estaria reiterando seu entendimento anterior, sem que lhe fosse possível imputar algum tipo de ativismo judicial. Também, não se pode desprezar que os dados de Carvalho Neto (2005) sugerem um controle menor de constitucionalidade dos atos normativos federais, ao menos quando comparado com o dos estaduais.

Ainda assim, o percentual de 83,3\% de declarações de inconstitucionalidade permanece alto segundo parâmetros estatísticos. Ademais, a pesquisa de Carvalho Neto limitou-se a quantificar dados da judicialização de atos normativos federais, enquanto os dados do STF são mais sólidos por contemplarem toda população de Ações já julgadas. Apesar de existirem diferenças na amplitude do controle de constitucionalidade dos atos normativos federais e estaduais, não há dúvida de que existe um número significativo de declarações de inconstitucionalidade no Brasil, sendo pouco crível a tese de que haveria certa passividade da Corte.

Por fim, as duas últimas pesquisas empíricas a serem comentadas são de Matthew Taylor e Eduardo Leoni e Antônio Ramos. Em ambas, as decisões do STF são analisadas com recursos estatísticos sofisticados.

Taylor (2006, p. 18ss) procurou compreender como cinco variáveis afetam a probabilidade de haver a suspensão da eficácia de normas em sede cautelar. São elas: legitimados ativos, área da lei, tipo da lei, se o legitimado ativo é uma associação ou organização jurídica e, por fim, qual presidente da República estava no poder ao tempo em que a lei foi promulgada. As hipóteses testadas pelo modelo estatístico foram:

I. Atores estatais (Mesas dos Poderes Legislativos, chefes do Poder Executivo e o Procurador da República) possuem maiores chances de obter a declaração 
de inconstitucionalidade devido aos recursos disponíveis para tanto (Taylor, 2006, p. 18).

II. Partidos políticos possuem menor chance de sucesso que os anteriores em razão do fato de usarem o STF para, meramente, demonstrar sua insatisfação com a norma, ao invés de atacá-la com bons argumentos jurídicos (Taylor, 2006, p. 19).

III. Normas que suscitam supermaiorias para a aprovação diminuem a probabilidade de declaração de inconstitucionalidade; normas que não exigem grande rigor na aprovação, como os regulamentos, aumentam a probabilidade de declaração de inconstitucionalidade (Taylor, 2006, p. 19).

IV. As associações ou organizações jurídicas gozam da maior probabilidade de obterem sucesso na judicialização, dados os recursos disponíveis (Taylor, 2006, p. 20).

V. O Presidente que sancionou a lei influencia a probabilidade de declaração de inconstitucionalidade (Taylor, 2006, p. 20).

VI. Áreas temáticas das normas podem importar aumento na probabilidade de declaração de inconstitucionalidade (Taylor, 2006, p. 19).

Após testar o modelo, as hipóteses I, II, IV, VI e, parcialmente, a III foram confirmadas. A hipótese III não foi confirmada completamente porque a legislação ordinária aumentou a probabilidade de declaração de inconstitucionalidade, quando comparada aos regulamentos. Assim, o grau de deliberação, se dificultoso ou não, não assegura "imunidade" contra uma eventual declaração de inconstitucionalidade, afirmou Taylor (2006, p. 21, 23).

Taylor apontou que as Ações Diretas de Inconstitucionalidade funcionam como "ponto de veto" (veto point) para que os atores jurídicos possam atuar como uma espécie de veto player. O STF operaria como um fórum alternativo de discussão das políticas aprovadas pelo Parlamento ou pelo Executivo, já que esses grupos não possuem voz junto ao Executivo e a atuação junto ao Parlamento seria muito custosa (Taylor, 2006, p. 23).

Por fim, Leoni e Ramos, a partir da estimação de pontos ideais dos Ministros do STF, observaram que as preferências dos ministros do STF se aproximam, cada vez mais, das preferências dos chefes do Executivo. Isso decorreu não de qualquer relação de dependência para com os presidentes, mas de, simplesmente, uma espécie de coincidência entre as preferências dos ministros e dos chefes do Executivo. Para esses 
autores, quando o presidente procura implementar uma agenda contrária à maioria parlamentar ou à Constituição, tudo leva a crer, a partir dos dados coletados por eles, que a Corte tende a dar menos suporte ao Presidente; se, por outro lado, o presidente age de maneira oposta à anterior, as preferências da Corte tendem a ser mais próximas das do Executivo (Leoni e Ramos, 2006, p. 13).

\section{Política e custos econômicos da declaraçÃo DE INCONSTITUCIONALIDADE}

Como vimos, as pesquisas empíricas demonstraram a sensibilidade do STF às variáveis políticas. De uma maneira geral, elas reforçaram a tese corrente de que a Corte é um órgão político ou de governo. Neste artigo, contudo, gostaríamos de enfatizar outra abordagem, pois as pesquisas, apenas, deram atenção a fatores políticos e, muito indiretamente, focaram variáveis econômicas. Procuraremos, então, suprir essa lacuna demonstrando que além do STF responder às variáveis jurídicas e políticas ele declara a inconstitucionalidade de normas, se o ato normativo atacado aumenta os custos orçamentários para o Estado, isto é, provoca um impacto econômico negativo nas contas estatais.

Para tanto, torna-se necessário delimitar uma amostra de casos a serem quantificados, para fins de análise estatística. Como o foco neste texto é a atuação do Supremo Tribunal Federal após 1998, afastamos, desde logo, a investigação de todas as Ações Diretas de Inconstitucionalidade que foram ajuizadas até esse ano. Na prática, isso significa que não analisamos o conjunto das Ações que vai da ADI n. 1 até a ADI n. 1939, pois as Ações foram ajuizadas até 1998.

Houve, ainda, uma necessidade de delimitação do termo final da pesquisa, seja por razões acadêmicas, seja por razões práticas. Assim, somente investigamos Ações ajuizadas entre os anos 1999 e 2004. Isso significa que a pesquisa se centrou nas análises das ADI n. 1940 a ADI n. 3382, contudo, nem todas interessavam, pois havia duas decisões principais em uma Ação Direta de Inconstitucionalidade, as cautelares e as definitivas. Qualquer pesquisa que deseje investigar o processo decisório no Supremo Tribunal Federal terá que fazer opções que vão interferir, definitivamente, nos resultados finais da investigação: ou se analisa cautelares, ou se analisa decisões finais, ou ambas.

Em geral, o trabalho de análise dos dados primários e de quantificação dos mesmos é feito por grupos de pesquisa, pois ele demanda uma enorme quantidade de tempo e recursos. Como o trabalho aqui apresentado foi feito de maneira solitária pelo pesquisador, tornou-se necessário diminuir a amostra e fazer opções metodológicas capazes de garantir a validade dos resultados, sem perda de rigor.

A primeira delas foi escolher investigar apenas as decisões finais do Supremo Tribunal Federal. A razão é simples: nas decisões finais, podemos ter uma dimensão 
melhor de quais são os resultados definitivos das Ações Diretas de Inconstitucionalidade. Nas decisões cautelares, ao contrário, há a possibilidade de reversão da decisão cautelar pela decisão final ou, ainda, as justificativas utilizadas pela Corte tendem a ser provisórias e/ou superficiais. Ao analisar as decisões finais, estamos garantindo que iremos teorizar sobre decisões definitivas, o que acarreta uma diminuição da incerteza quanto aos resultados finais do processo decisório no Supremo Tribunal Federal.

A segunda opção reside no fato de investigarmos apenas as decisões colegiadas do Supremo Tribunal Federal. Dentre as diversas decisões finais possíveis, há a possibilidade de a decisão final haver sido tomada, monocraticamente, por um Ministro Relator. Como essas decisões são o resultado da extinção do processo sem a apreciação do mérito, a decisão final e os fatores que levaram até ela são bem previsíveis, tais quais: ilegitimidade ativa superveniente, revogação da norma atacada, deficiências na representação processual, inépcia da petição inicial, entre outros. Assim, preferimos focar nossa pesquisa nas decisões tomadas pelo Plenário do STF.

Há, entretanto, uma razão mais técnica para desconsiderar as decisões tomadas monocraticamente: estamos preocupados em aferir o comportamento da Corte nas decisões finais. Nas decisões monocráticas observa-se apenas o comportamento de um único ministro. Além disso, em decisões monocráticas, prevalecem motivos de ordem processual para a extinção do processo e, em geral, a aferição da presença ou não de circunstâncias que levam à extinção é relativamente automática, sem discussões mais aprofundadas.

Uma vez que estávamos interessados unicamente em entender o comportamento do Plenário da Corte, restou a opção de delimitar um decurso temporal. A pergunta, então, toma outra natureza: Que decurso temporal analisar?

Como vimos, a pesquisa de Vianna et al. (1999) cobre o processo decisório do STF até o ano de 1998. Descartamos, então, investigar as Ações Diretas de Inconstitucionalidade desse período e optamos pelas Ações ajuizadas no período de 1999 a 2004 e julgadas até 31 de dezembro de 2006, data final da pesquisa. Após listarmos e quantificarmos provisoriamente as 1.443 Ações em um software estatístico, pudemos constatar que somente 358 foram decididas definitivamente pelo Plenário. Outras 404 foram julgadas monocraticamente, uma vez que não foram conhecidas ou resultaram em perda superveniente do objeto. As demais 681 Ações ainda não tinham sido decididas em caráter definitivo à época.

Nossa amostra inicial caiu, portanto, para 358 Ações. Esse foi o número total de casos decididos pelo plenário até o fechamento de nossa pesquisa em 31 de dezembro de 2006. Ainda por razões estatísticas, teríamos de separar Ações que analisaram questões relevantes de política de governo daquelas que diziam respeito à sociedade ou apenas indiretamente ao Estado. Para isso, procuramos analisar uma amostra que envolvesse apenas decisões em questões de Estado cuja judicialização pudesse ensejar risco de grande impacto orçamentário negativo nas contas públicas, tais quais: organização do 
Estado, tributação, finanças públicas e outros assuntos congêneres. As decisões da Corte, nesses âmbitos, possuem uma repercussão maior nos interesses dos atores políticos envolvidos pelo processo decisório do STF, razão pela qual atraem uma discussão maior de custos associados à decisão.

Esses casos foram 191, ao todo. Desses, 38 decisões foram tomadas por maioria e 153 decisões, por unanimidade. Dentro desses valores, entretanto, estão as Ações Diretas de Inconstitucionalidade por Omissão. Como, a princípio, o processo decisório que envolve a judicialização das omissões normativas é muito diferenciado daquele das inconstitucionalidades por ação, decidimos suprimi-las da amostra. Diante disso, nossa amostra final de decisões a serem analisadas por uma técnica estatística denominada regressão logística ficou em 162 casos.

Para fins classificatórios, as temáticas denominadas questões de Estado foram as que envolveram a discussão em torno da constitucionalidade de normas que versam sobre estes assuntos:

- Normas de disciplina do regime jurídico tributário (direitos e deveres tributários do contribuinte e da administração tributária);

- Normas de disciplina do regime jurídico das finanças públicas (organização do orçamento público e atividade financeira do Estado);

- Normas sobre o sistema bancário, planos de estabilização monetária e moeda;

- Normas de regulação da disciplina jurídica dos benefícios previdenciários do regime geral de previdência social;

- Normas sobre organização e gerência das administrações direta e indireta;

- Normas sobre a carreira, direitos, deveres e disciplina remuneratória dos servidores públicos e agentes políticos;

- Normas de regulação do regime de benefícios previdenciários dos servidores públicos estatutários (civis e militares);

- Normas de regulação da disciplina jurídica das privatizações.

As decisões que versam sobre as demais temáticas (p.ex., normas sobre o regime eleitoral e partidário, normas sobre direitos trabalhistas dos não servidores, normas não enquadráveis nas categorias das questões de Estado) não foram analisadas. Aparentemente, essa distinção dos casos, entre questões de Estado e outras temáticas, 
pode parecer inócua, mas, de fato, não é. A tabela 1, na qual constam os dados de nossa amostra, demonstra isso claramente.

Tabela i. Área temática Versus tipo de DeCisão.

\begin{tabular}{llll} 
& DECISÃO POR MAIORIA & DECISÃO UNÂNIME & TOTAIS \\
\hline QUESTÕES DE ESTADO & 38 & 124 & 162 \\
\hline OUTRAS & 62 & 103 & 165 \\
\hline TOTAIS & 100 & 227 & 327
\end{tabular}

Fonte: banco de dados do autor.

A tabela 1 evidencia que áreas temáticas não relacionadas a questões de Estado tiveram um dissenso jurisprudencial significativamente maior que as áreas relacionadas a essas questões. Do total de 162 decisões a serem analisadas por regressão logística, 124, ou seja, 76,5\% delas, foram unânimes, enquanto das 165 decisões das outras temáticas, apenas 103 decisões foram unânimes, o que representa 62,4\%. Testes estatísticos demonstraram a significância dessa diferença.

Outra maneira de visualizar isso é analisando o número de decisões por maioria nas duas áreas temáticas. Enquanto nas temáticas relacionadas a questões de Estado houve decisão por maioria em 38 casos do total de 162 casos, nas outras áreas houve 62 decisões por maioria, para um total de 165 casos, apesar de ambas as temáticas possuírem um número praticamente idêntico de decisões finais (162 e 165).

Claramente, há uma tendência a maior consenso, entre os Ministros, quando decidem casos relacionados a questões de Estado, ao menos quando comparados com o processo decisório dos casos das demais áreas temáticas. Isso se deve, provavelmente, aos custos associados à decisão. Como, em tese, os riscos econômicos e políticos são maiores nas questões de Estado, os ministros tendem a tomar decisões de maior consenso, pois são induzidos a minimizar esses riscos.

\section{Modelo estatístico de Regressão logística e variáveis anAlisadas} Uma vez delimitados os casos a serem analisados, passemos à análise estatística. Faremos uso de um modelo de regressão, para que possamos quantificar as probabilidades ou chances de uma declaração de inconstitucionalidade. Em estatística, a regressão é um modelo matemático que procura investigar como as variações em uma variável denominada dependente (ou endógena) podem ser explicadas por uma ou mais variáveis independentes (exógenas ou explicativas) (cf. Gujarati, 2000, p. 3-34). 
A variável dependente é a variável que o pesquisador deseja investigar, a declaração ou não de inconstitucionalidade de uma norma em nossa pesquisa. As variáveis independentes, por sua vez, são os diversos fatores - político, jurídico e econômico - que acreditamos influenciar a decisão por declarar ou não a inconstitucionalidade de uma norma.

Por ora, deve-se, apenas, esclarecer que existem diversos tipos de regressão em estatística. Em comum, qualquer modelo de regressão, para uma visão moderna, é, apenas, uma tentativa de sumarizar as informações encontradas em um banco de dados coletados por pesquisadores (Powers e Xie, 2000, p. 17).

O modelo a seguir, portanto, tenta testar o peso de eventuais variáveis jurídicas, políticas e econômicas no processo decisório das Ações Diretas de Inconstitucionalidade por Ação dos processos que julgam assuntos relacionados às questões de Estado. Para isso, calculamos uma regressão logística múltipla, com o intuito de aferir o real peso dessas variáveis na decisão final da Corte.

Em nosso modelo, a variável dependente identifica os casos em que o STF "declarou a inconstitucionalidade da norma” (código 1) em oposição aos que, simplesmente, "entendeu que a norma seria constitucional" ou, por razões processuais, "declarou o não conhecimento ou a perda do objeto da Ação” (código 0). As variáveis independentes foram subdivididas em dois tipos. No primeiro estão as variáveis econômica e política, que procuram aferir a "sensibilidade do STF às questões que possam gerar impacto econômico negativo ao Estado, aos atores envolvidos" no processo de judicialização da política e aos "interesses do presidente da República”. Vejamos:

a) Impacto negativo. Essa variável foi categorizada com o código 1, se a norma que está sendo atacada gera maiores custos orçamentários para o Estado; e 0, se a norma não gerou qualquer impacto ou se foi positiva, economicamente, para o Estado, trazendo, por exemplo, maior arrecadação tributária.

b) Ator jurídico. Variável que distingue os legitimados ativos em dois grupos: atores jurídicos e atores não jurídicos. A classificação, originalmente, seguia a distinção feita por Ernani Carvalho (2006, anexo I) entre os atores sociais, jurídicos e políticos. Após o uso de testes estatísticos (testes de verossimilhança), chegamos à especificação final dessa variável. Portanto, a variável ator jurídico pode assumir duas categorias: 1, se o legitimado foi um ator jurídico (Conselho Federal da OAB, procurador-geral da República e confederações ou entidades de classe ligadas aos membros das carreiras jurídicas); e 0, se ator político ou social (demais legitimados).

c) Interesse do presidente. Mensura o interesse do presidente da República no desfecho da Ação Direta de Inconstitucionalidade por Ação e como o STF reage ao mesmo. Como não é fácil atribuir preferências ao presidente da República, existe alguma dose 
de subjetividade na caracterização dessa variável. Taylor (2006, p. 20), por exemplo, optou por uma definição mais objetiva de uma variável que acessasse o peso do presidente nas decisões do STF, e incluiu em seu modelo uma variável para indicar que presidente governava o Brasil ao tempo em que a lei foi promulgada e publicada.

Com uma especificação desse tipo, não foi surpresa Taylor não ter encontrado qualquer significância estatística em sua variável, pois nem toda lei aprovada pelo Congresso Nacional está na agenda prioritária do governo. Ao contrário, a regra é que, do universo de leis aprovadas, poucas estejam sob o foco da atenção especial do governo federal. Assim, não há porque o STF estar preocupado em declarar ou não a inconstitucionalidade de normas a partir desse critério.

Por outro lado, a abordagem que entendemos mais profícua seria entrevistar os antigos presidentes para aferir seus interesses reais na constitucionalidade ou não de uma lei. Como, em nossa pesquisa, isso foi inviável, optamos por atribuir preferências. Assim, consideramos que o presidente teria interesse na constitucionalidade da norma, se a norma que estivesse sendo atacada versasse sobre medidas decorrentes do ajuste fiscal, da reforma da Previdência ou da reforma administrativa. O interesse seria pela inconstitucionalidade se as normas atacadas fossem contrárias a essa agenda. Por fim, se as normas não versam sobre os temas supramencionados, assumimos que o presidente não teria qualquer interesse no desfecho da ADI. Portanto, a variável é uma dummy com a especificação que segue: 1, se o presidente possui interesse na constitucionalidade da norma; e 0 , se o presidente é indiferente à norma ou possui interesse na inconstitucionalidade da norma.

A variável de segundo tipo foi denominada de "iniciativa do Executivo" e mensura o peso de concepções jurídicas nas decisões finais da Corte. O STF, por meio de reiterada jurisprudência, pacificou o entendimento de que as regras pertinentes ao processo legislativo, na esfera federal, devem ser aplicáveis à esfera estadual e, em especial, entendeu que isso incluiria, inclusive, as regras sobre o direito de iniciativa legislativa (cf., p.ex., ADI 2115, ADI 2079 e ADI 2808). No âmbito federal, o presidente da República, por força do artigo $61, \S 1^{\circ}$, da $\mathrm{CF} / 88$, possui iniciativa privativa em algumas matérias, gozando de grande poder de agenda. O Congresso Nacional, ao apreciar esses projetos, poderá alterá-los, desde que isso não implique aumento de despesa (art. 63, I, da CF/88). Se, por um lado, não há dúvidas de que isso é válido na esfera federal, por outro, o STF, fundado na convicção normativa de que o princípio da separação de poderes exige que esse mesmo modelo da esfera federal seja aplicável aos Estados, inclusive no pertinente ao direito de iniciativa do chefe do Executivo, terminou por assentar uma jurisprudência favorável à proteção do direito de formação da agenda legislativa dos governadores. Com isso, o STF abriu espaço para uma ampla judicialização da política local dos Estados e permitiu que os governadores tivessem acesso a uma nova arena decisória, caso suas 
preferências políticas viessem a ser lesadas pelas Assembleias Legislativas de seus Estados de origem.

Observe-se que a orientação dada pelo STF é apoiada em uma convicção normativa não facilmente enquadrável no estereótipo liberal/conservador. Antes, parece estar assentada em uma construção doutrinária incentivada pela própria Constituição de 1988, que consagrou o princípio da separação dos poderes e enunciou regras relativamente detalhadas sobre o funcionamento do processo legislativo. Essa variável, portanto, é uma maneira de avaliar o peso de comportamentos normativos na decisão final do STF, o peso da jurisprudência na explicação final de como o STF decide seus casos.

Com essa breve exposição, torna-se possível enunciar os resultados do modelo de regressão logística. Na verdade, antes de chegarmos até sua versão final, vários testes estatísticos foram realizados. Particularmente, foram elaboradas várias especificações com diferentes variáveis. Os testes estatísticos de verossimilhança e a estatística (Bayesian Information Criterion (BIC) apontaram o modelo apresentado na tabela 2 como o mais adequado aos dados do banco:

TAbela 2. Modelo de Regressão logística.

\begin{tabular}{llll}
$\begin{array}{l}\text { VARIÁVEIS } \\
\text { INDEPENDENTES }\end{array}$ & $\beta$ & $\begin{array}{l}\text { EXP( } \beta \text { I } \\
\text { RAZÃO DAS CHANCES } \\
\text { (ODDS RATIO) }\end{array}$ & $\mathrm{P}>\mathbf{Z}$ \\
\hline ATOR JURÍDICO & 1,15 & 3,16 & 0,016 \\
\hline INICIATIVA DO EXECUTIVO & 1,76 & 5,78 & 0,001 \\
\hline IMPACTO NEGATIVO & 1,0064 & 2,73 & 0,009 \\
\hline INTERESSE DO PRESIDENTE & $-1,76$ & 0,17 & 0,026 \\
\hline
\end{tabular}

Fonte: banco de dados do autor.

Nesse momento, deve-se fazer uma advertência: o leitor que não possui intimidade com estatística deve atentar, apenas, aos resultados que serão apresentados nos parágrafos que seguem.

Primeiramente, precedentes são decisivos para compreensão da decisão final do STF, pois os casos que suscitaram discussão em torno das regras do poder de iniciativa importaram um aumento nas chances de declaração de inconstitucionalidade de 5,8 vezes, quando comparados aos casos que não suscitam a aplicação desse entendimento do STF.

Até então, não há novidade para o público da área jurídica: a jurisprudência pacificada importa, pois os magistrados tendem a decidir de acordo com ela! Fatores 
políticos, todavia, são também decisivos para o desfecho das Ações Diretas de Inconstitucionalidade por Ação. Em primeiro lugar, os atores jurídicos foram mais bem-sucedidos em conquistar a declaração de inconstitucionalidade que os demais, pois as chances dos atores jurídicos de conseguirem uma declaração de inconstitucionalidade são 3,2 vezes superiores às chances dos demais atores serem bem-sucedidos.

O STF pareceu ser sensível também aos interesses do presidente da República. Se o presidente tinha interesse na constitucionalidade da norma, isso reduziu as chances de declaração de inconstitucionalidade em 0,17. Em uma linguagem mais clara, isso significa que as chances do STF de não declarar a inconstitucionalidade, quando a norma está dentro da agenda do presidente, são 5,8 vezes superiores às situações nas quais o presidente é indiferente à mesma.

Como previsto, o STF também foi sensível ao impacto econômico da norma jurídica: se a norma está provocando impactos econômicos negativos nas contas do poder público, as chances do STF declarar sua inconstitucionalidade são 2,7 vezes superiores, quando comparadas com os casos em que as normas geram impactos positivos ou neutros.

\section{DISCUSSÃO DOS RESULTADOS}

Os resultados apresentados anteriormente foram significativos e merecem alguns comentários.

Primeiramente, o relativo sucesso que os atores jurídicos possuem suscita algumas discussões interessantes. Taylor (2006, p. 19ss), examinando Ações que atacavam normas federais, encontrou significância em uma variável que distinguia os atores estatais dos demais atores. Ao incluir essa variável no modelo deste trabalho, ficamos surpresos ao descobrir que isso havia acarretado a ausência de significância da variável "impacto negativo", embora a variável dummy que indicava ser o legitimado um ator jurídico continuasse a ser significante. O procedimento estatístico padrão seria usar um teste estatístico para verificar que modelo teria mais adequação aos dados coletados. Como resultado, pudemos rejeitar a utilização da variável de Taylor em benefício do modelo desenvolvido neste trabalho. Assim, atores jurídicos têm maior sucesso na judicialização que os demais atores.

Outro ponto testado foi a hipótese de Ernani Carvalho Neto (2005) da seletividade e da especificidade do processo decisório na Corte. Para isso, testamos modelos que incluíam, como variável, o procurador-geral da República em oposição aos demais atores ou mesmo variáveis que avaliavam se a Corte possuía alguma preferência pelos partidos políticos, procurador-geral da República e governador em detrimento dos demais legitimados ativos. Como resultado, chegamos à conclusão de que, realmente, o procurador-geral da República obtém mais sucesso na judicialização do que os demais 
atores. No entanto, após a utilização de testes estatísticos, a tese de Ernani Carvalho foi rejeitada em favor da variável que distinguia apenas os atores jurídicos dos não jurídicos.

A razão para isso pôde ser visualizada a partir de estatísticas descritivas. Em nossos dados, outros atores também obtiveram sucesso na judicialização da política. Embora o procurador-geral da República figurasse com um percentual de sucesso da ordem de 80\% de suas demandas, o Conselho Federal da OAB e as demais entidades de classe jurídicas conseguiram um percentual de sucesso da ordem de 60\% e 62,5\%, respectivamente. Parece, então, apressado entender que o Supremo Tribunal Federal teria, como único parceiro, o procurador-geral da República.

Testamos também a hipótese de especificidade, incluindo uma variável para a área temática da norma atacada pela ADI em nosso modelo. Após a regressão logística, a única área que significativamente possuiu uma judicialização maior que as outras foi a pertinente ao controle de constitucionalidade das normas sobre o regime jurídico e a disciplina remuneratória dos servidores. Após utilizarmos testes estatísticos, entretanto, houve a indicação de que a variável concernente à área temática não deveria ser incluída no modelo. Há de se concluir, portanto, que o STF não escolhe áreas para judicializar a política.

Por fim, a significância da variável que mensura o interesse do presidente no desfecho da Ação Direta de Inconstitucionalidade também apresenta uma boa base para desenvolvermos discussões importantes. Sabemos que, em nossa ordem constitucional, o presidente da República não possui meios eficientes para controlar os ministros do Supremo Tribunal Federal, especialmente em função das garantias constitucionais do artigo 95 da CF/88. A significância dessa variável, contudo, pode deixar transparecer que queremos defender o contrário. Na verdade, essa não é a proposta, pois não há razões para crer que o STF decide de acordo com as preferências do presidente em decorrência de receio de possível retaliação. Parece que a explicação mais plausível da significância dessa variável reside em dois pontos.

Em primeiro lugar, uma norma que manifeste a agenda do presidente da República pode ser um sinal para o STF de que a Corte deve possuir cautela ao decidir, pois isso pode implicar alterações substanciais no curso de uma política. A segunda razão pode estar no legitimado ativo que provoca os ataques às normas de interesse do presidente da República. A tabela 3 ilustra o porquê dessa última afirmativa. 
TABela 3. Legitimados ATIVOS Versus INTERESSE DO PRESIDENTE.

\begin{tabular}{|c|c|c|c|}
\hline LEGITIMADOS ATIVOS & $\begin{array}{l}\text { O PRESIDENTE NÃO POSSUI } \\
\text { INTERESSE NA ADI* }\end{array}$ & $\begin{array}{l}\text { O PRESIDENTE POSSUI } \\
\text { INTERESSE NA DECLARAÇÃO } \\
\text { DE CONSTITUCIONALIDADE }\end{array}$ & TOTAIS \\
\hline MESAS DO PL & 1 & 2 & 3 \\
\hline GOVERNADOR & 75 & 2 & 77 \\
\hline PGR & 19 & 1 & 20 \\
\hline CF DA OAB & 5 & 0 & 5 \\
\hline PARTIDOS POLÍTICOS & 18 & 14 & 32 \\
\hline CONFEDERAÇÕES & 10 & 1 & 11 \\
\hline ENTIDADE DE CLASSE & & & \\
\hline DE ÂMBITO NACIONAL & 10 & 3 & 13 \\
\hline TOTAIS & 138 & 23 & 161 \\
\hline
\end{tabular}

*Nos dados, não foram vislumbrados casos em que houve interesse na declaração de inconstitucionalidade.

Fonte: banco de dados do autor.

Como vemos, $60,87 \%$ dos ataques às normas de interesse do presidente advêm dos partidos políticos. Nesse sentido, talvez uma explicação plausível, para a deferência do STF para com a agenda do presidente, esteja na própria lógica das Ações Diretas de Inconstitucionalidade por Ação dos partidos políticos. Como salienta Taylor (2006, p. 18), em outro contexto, os partidos políticos possuem menos probabilidade de serem bem-sucedidos nas Ações porque parte expressiva dessas pode estar simplesmente relacionada à utilização do STF para fins meramente políticos. O questionamento vem, então, não como uma tentativa de atacar inconstitucionalidades em si, mas simplesmente manifestar uma discordância política para com a norma produzida na arena parlamentar.

\section{Conclusão}

O processo decisório das Ações Diretas de Inconstitucionalidade por Ação está permeado de múltiplas variáveis. Longe de serem influenciadas somente por questões estritamente jurídicas, as decisões do STF também são sensíveis a fatores de ordem política e econômica. Consistente com a literatura política no Brasil, esta pesquisa 
reforçou a conclusão de que o STF age como policy maker, tomando decisões como órgão de governo, e não como instituição jurídica neutra ao ambiente econômico e político. Por outro lado, apresentou várias evidências estatísticas de que o processo decisório tem uma lógica própria.

De uma maneira geral, a partir da utilização do modelo estatístico de regressão logística, pode-se afirmar que o STF declara a inconstitucionalidade de normas que causam impacto orçamentário negativo nas contas estatais, mas evita declarar a inconstitucionalidade de normas que estejam na agenda do presidente da República. Também é extremamente sensível aos atores que provocam a jurisdição constitucional abstrata, pois as chances dos atores jurídicos de obterem sucesso na judicialização são significantemente maiores que as dos demais atores. Por fim, a jurisprudência também importa como mecanismo explicativo do processo decisório.

As conclusões sugerem que o STF não possui um só tipo de comportamento ao julgar. Embora aja como órgão de governo, também decide de acordo com cânones jurídicos (jurisprudência pacificada). Por outro lado, o maior dissenso jurisprudencial, ao julgar questões envolvendo outros temas não relacionados a questões de Estado, indica que o STF pode ser movido por preferências políticas/ideologias também nas Ações que não envolvem questões de Estado. Mais pesquisas, entretanto, precisam ser realizadas sobre esse ponto.

: ARTIGO APROVADO (01/06/2012) : RECEBIDO EM 12/05/2011

\section{REFERÊNCIAS BIBLIOGRÁFICAS}

ARANTES, Rogério Bastos. Judiciário e política no Brasil. São Paulo: Educ/Fapesp/Idesp, 1997. BERGARA, Mario; RICHMAN, Barak; SPILLER, Pablo. Modeling Supreme Court Strategic Decision Making: The Congressional Constraint. Universidad de la Republica/Departamento de Economia, p. 1-44, dez. 2002.

CARVALHO, Ernani Rodrigues de. Em busca da judicialização da política no Brasil: apontamentos para uma nova abordagem. Revista sociologia e política. Curitiba, n, 23, p. 115-126, nov. 2004.

CARVALHO, Ernani Rodrigues de. Revisão judicial e judicialização da política no Brasil: seletividade e especificidade. IV encontro da ABCP. Belo Horizonte: Fafich/UFMG, jul. 2006.

CARVALHO NETO, Ernani Rodrigues de. Revisão abstrata da legislação e judicialização da política no Brasil. 2005. São Paulo: USP/Departamento de Ciência Política, Tese de doutoramento.

CASTRO, Marcus Faro de. Política e Economia no Judiciário: as ações diretas de inconstitucionalidade dos partidos políticos. Cadernos de ciência política. Brasília: UNB, n. 7, p. 1-59, 1993.

CASTRO, Marcus Faro de. O Supremo Tribunal Federal e a judicialização da política. Revista brasileira de ciências sociais. São Paulo: Anpocs, v. 12, n. 34, p. 147-156, 1997. 
EPSTEIN, Lee; KNIGHT, Jack. The Choices that Justices Make. Washington D. C.: CQ Press, 1998. EPSTEIN, Lee; MERSHON, Carol. Measuring political preferences. American journal of political science, v. 40, n. 1, p. 261-294, Feb. 1996.

GUJARATI, Damodar. Econometria básica. São Paulo: Makron/Pearson, 2000.

JUNQUEIRA, Eliane Botelho. A sociologia do direito no Brasil: Introdução ao debate atual. Rio de Janeiro: Lúmen Júris, 1993.

LEONI, Eduardo; RAMOS, Antônio. Judicial preferences and judicial independence in new democracies: the case of the Brazilian Supreme Court. Disponível em: www.columbia.edu/ ell2002/. Acesso em: 10 nov. 2006.

MAUÉS, Antônio; FADEL, Alexandre. Circuitos interrompidos: as adins dos partidos políticos no supremo tribunal federal (1999-2004). Anais do XV Congresso Nacional do CONPEDI - Manaus 17-18 Nov. 2006. Disponível em: www.conpedi.org.br/manaus/arquivos/anais/manaus/ direito_e_politica_antonio_m_maues_e_alexandre_fadel.pdf. Acesso em: 21 mar. 2011.

OLIVEIRA, Vanessa Elias de. Judiciário e privatizações no Brasil: existe uma judicialização da política? Revista dados. Rio de Janeiro, v. 48, n. 3, p. 559-587, 2005.

PERRY, Hersel. Deciding to decide: agenda setting in the United States Supreme Court. Massachusetts: Harvard University Press, 1991.

POWERS, Daniel; XIE, Yu. Statistical Methods for Categorical Data Analysis. San Diego: Academic Press, 2000. SADEK, Maria Tereza. Estudos sobre o sistema de justiça. In: MICELI, Sérgio. (Org.) O que ler na ciência social brasileira 1970-2002. São Paulo: Sumaré, v. 4, 2002, p. 233-265.

SEGAL, Jeffrey. Separation-of-powers games in the positive theory of congress and courts. The American Political Science Review, v. 91, n. 1, p. 28-44, Mar. 1997.

SEGAL, Jeffrey; SPAETH, Harold. The Supreme Sourt and the Attitudinal Model Revisited. Cambridge: Cambridge University Press, 2002.

STF. Ações diretas de inconstitucionalidade - 1988-2011. Disponível em: www.stf.jus.br/portal/cms/ verTexto.asp?servico=estatistica\&pagina=adi. Acesso em: 25 abr. 2011.

TAYLOR, Matthew. Veto and voice in the courts: policy implications of institutional design in Brazilian judiciary. Disponível em: www.econ.fea.usp.br/seminarios/2005_1/matthew_taylor.pdf. Acesso em: 20 nov. 2006.

VIANNA, Luis Werneck et al. A judicialização da política e das relações sociais no Brasil. Rio de Janeiro: Revan, 1999.

VIEIRA, Oscar Vilhena. Supremo Tribunal Federal: Jurisprudência política. São Paulo: RT, 1994.

\section{Ricardo Silveira Ribeiro}

Av. Gil de Abreu Souza, n. 5000 Condomínio Golden Hill, Q. 2, Casa 9 Esperança - 86058-100 Londrina - PR - Brasil ricardoribeirolagu.gov.br
Doutor em Direito Público PELA Universidade Federal de Pernambuco (UFPE)

PROFESSOR-TITULAR DA UNIVERSIDADE Norte do PARANÁ EM LONDRINA (UNOPAR) 